\title{
A POLÍTICA DE ASSISTÊNCIA SOCIAL EM CONSTRUÇÃO E O DESAFIO DA GARANTIA DE DIREITOS HUMANOS DAS CRIANÇAS E ADOLESCENTES: aspectos de violência estrutural e simbólica
}

\author{
Cândida da Costa \\ Universidade Federal do Maranhão (UFMA)
}

\begin{abstract}
A POLÍTICA DE ASSISTÊNCIA SOCIAL EM CONSTRUÇÃO E O DESAFIO DA GARANTIA DE DIREITOS HUMANOS DAS CRIANÇAS E ADOLESCENTES: aspectos de violência estrutural e simbólica

Resumo: 0 artigo aborda a violência estrutural e simbólica que impede que sejam assegurados os direitos humanos das crianças e adolescentes no Estado do Maranhão. Analisa as falhas e avanços da política de Assistência Social na garantia dos direitos básicos de todas as pessoas que, por várias razões, encontram-se em situações de vulnerabilidade ou risco social. Para avaliar a necessidade e a efetividade dessa política pública, identifica e analisa indicadores gerais de população, renda e acesso aos serviços públicos e indicadores específicos de cobertura em relação às situações de vulnerabilidade e risco, PIB e indicador de desenvolvimento humano (IDH) no Estado e no Brasil. Além disso, traz o debate que cerca o tema da redução da maioridade penal.
\end{abstract}

Palavras-chave: Direitos humanos, crianças e adolescentes, assistência social, redução da maioridade penal.

THE SOCIAL ASSISTANCE POLICY IN CONSTRUCTION AND THE CHALLENGE OF WARRANTY OF HUMAN RIGHTS OF CHILDREN AND ADOLESCENTS: aspects of structural and symbolic violence

Abstract: The article discusses the structural and symbolic violence that prevents the human rights of children and adolescents are provided in the State of Maranhão. We analyze the failures and advances in social assistance policy in ensuring the basic rights of all persons who, for various reasons, find themselves in situations of social vulnerability or risk. To assess the need and the effectiveness of this policy, identifies and analyzes general indicators of population, income and access to public services and specific coverage indicators in relation to situations of vulnerability and risk, PIB and Human Development Indicator (IDH) in the State and in Brazil. In addition, brings the debate surrounding the issue of reduction of criminal responsibility.

Key words: Human rights, children and adolescents, assistance social, reduction of criminal responsibility.

Recebido em: 19.08.2014 Aprovado em: 22.09.2014 


\section{INTRODUÇÃO}

A política de Assistência Social destina-se à garantia dos direitos básicos de todas as pessoas. Dessa forma, tem como beneficiários diretos todas as pessoas que, por diversas causas, encontram-se submetidas a situações de vulnerabilidade ou risco social. Para avaliar a necessidade e a efetividade dessa política pública, torna-se necessário identificar e analisar indicadores gerais de população, renda e acesso aos serviços públicos e indicadores específicos de cobertura em relação às situações de vulnerabilidade e risco. Além do debate que cerca o tema da redução da maioridade penal.

A violência estrutural tem suas causas centradas na desigualdade social gerada pelas relações capital versus trabalho e os cortes advindos das demais desigualdades como gênero, geração e etnia, dentre outras.

As desigualdades sociais singulares que 0 modo de produção capitalista produz são respondidas, no dizer de Santos (1995, p. 2), através dos sistemas de desigualdade e exclusão engendrados no capitalismo:

A desigualdade e exclusão são dois sistemas de pertença hierarquizada. No sistema de desigualdade, a pertença dá-se pela integração subordinada enquanto que no sistema de exclusão, a pertença dáse pela exclusão.

O processo de dominação simbólica ou violência simbólica se materializa em vários espaços da vida social dos maranhenses. Sob o controle de tal oligarquia, estão os meios de comunicação de massa com maior inserção junto à população maranhense, disseminando uma visão positiva da atuação dos governantes e mascarando a verdadeira situação socioeconômica do Estado (COSTA, 2000). Colaboram, assim, para engendrar o poder simbólico da oligarquia, enquanto poder de construção da realidade que tende a estabelecer o sentido imediato do mundo, especialmente, o mundo social (BOURDIEU, 1995).
Este artigo abordará indicadores referentes às seguintes questões no campo da Assistência Social que repercutem diretamente sobre os direitos humanos das crianças e dos adolescentes, tratando alguns elementos já publicados no Volume $\mathrm{V}$ do Observatório Criança (COSTA, 2013):

a) Dados populacionais;

b) Renda e pobreza;

c) Desenvolvimento humano;

d) Estruturação da política de assistência social no Estado do Maranhão;

e) Cobertura dos serviços e benefícios socioassistenciais;

f) Cobertura dos programas de transferência de renda;

g) Cobertura dos serviços de proteção especial a crianças e adolescentes.

Para desenvolver a avaliação da política de Assistência Social no Maranhão, foram consultadas diversas fontes secundárias. Entre essas, destacamse: o CENSO SUAS 2010, produzido pelo Ministério do Desenvolvimento Social e Combate à Fome (MDS); as pesquisas desenvolvidas pelo Instituto Brasileiro de Geografia e Estatística (IBGE), as edições do Atlas do Desenvolvimento Humano no Brasil, produzidas pelo Programa das Nações Unidas para o Desenvolvimento (PNUD), bem como os relatórios de gestão da Secretaria de Estado do Desenvolvimento Social do Maranhão (SEDES) e da Fundação da Criança e do Adolescente do Estado do Maranhão (FUNAC/MA).

\section{A CONFIGURAÇÃO DA POPULAÇÃO MARANHENSE}

Em 2010, o Maranhão atingiu a população de 6.574.789 habitantes, com uma densidade demográfica equivalente a $19,81 \mathrm{hab} / \mathrm{km}^{2}$. O crescimento populacional médio no período entre 2006 e 2010 foi de $1,5 \%$, o que elevou a população em $7,6 \%$ se comparada à população residente no estado em 2005. Esse ritmo de crescimento está entre os mais acelerados no país e na região Nordeste 
(INSTITUTO BRASILEIRO DE GEOGRAFIA E ESTATÍSTICA, 2010).

A evolução da população residente no estado entre 2006 e 2010 pode ser visualizada na Tabela 1.

Da população residente no estado em 2010, mais de $97 \%$ por cento eram originárias da região Nordeste, seguida da região Norte com quase 1,4\% (INSTITUTO BRASILEIRO DE GEOGRAFIA E ESTATÍSTICA, 2010).

Os dados censitários mostram clara tendência ao envelhecimento da população brasileira, com o estreitamento da base da pirâmide demográfica. Analisando a distribuição da população maranhense em função da idade, constata-se que, em 2010, mais de $41 \%$ dos habitantes situavam-se nas faixas etárias de 0 a 19 anos, percentual inferior ao registrado em 2005, que girava em torno de $45 \%$. Comparativamente, a população etária equivalia, em 2010, a $33 \%$, e a do Nordeste um pouco mais que $36 \%$. A Tabela 2 explicita essas relações.

Outra comparação importante para a compreensão do contexto dos direitos de crianças e adolescentes no estado é a taxa de urbanização. Enquanto no Brasil, em 2010, a taxa de urbanização ultrapassava o percentual de $84,4 \%$ e no Nordeste chegava a $73 \%$, no Maranhão esse percentual mal alcançava $63 \%$, o que o colocou na última posição no ranking nacional nesse indicador. A Tabela 3 indica essas proporções.

Os dados gerais mostram uma tendência ao envelhecimento da população, com menor proporção de crianças e jovens, mais acentuada nas áreas urbanas. Ao mesmo tempo, cresceu a proporção de domicílios chefiados por mulheres, que passou de $23,8 \%$, em 2000 , para $39,9 \%$, em 2010 (INSTITUTO BRASILEIRO DE GEOGRAFIA E ESTATÍSTICA, 2010).

Em relação à migração, o Maranhão recebeu na década de 2000 a 2010 um grande afluxo de pessoas vindas de outros estados - cerca de 260.000 pessoas, mas a migração entre os próprios municípios do estado é quase $100 \%$ superior à relacionada à oriunda de outros estados. Em relação à população que veio de outros estados, chama atenção 0 grande afluxo de pessoas vindas do Pará para se instalar no Maranhão.

\section{A SITUAÇÃO DE POBREZA NO MARANHÃO}

Os critérios adotados no Brasil para definir a situação de pobreza são bastante diferenciados entre os vários programas $\mathrm{e}$ políticas sociais. O Programa Bolsa Família, por exemplo, considera extremamente pobres as famílias com renda domiciliar per capita de até $R \$ 70,00$, e, pobres, aquelas com

Tabela 1 - Evolução da população residente - Maranhão, 2006 a 2010

\begin{tabular}{c|c|c}
\hline Ano & População & Variação (\%) \\
\hline 2006 & 6.184 .543 & $1,33 \%$ \\
\hline 2007 & 6.265 .102 & $1,30 \%$ \\
\hline 2008 & 6.305 .539 & $0,65 \%$ \\
\hline 2009 & 6.367 .111 & $0,98 \%$ \\
\hline 2010 & 6.574 .789 & $3,26 \%$ \\
\hline
\end{tabular}

Fonte: BRASIL. Ministério da Saúde. Departamento de Informática do SUS. Portal da Saúde. Brasília, DF, 2010. Disponível em:<http:// tabnet.datasus.gov.br/cgi/deftohtm.exe?ibge/cnv/popma.def>. Acesso em: 28 set. 2014.

Tabela 2 - Proporção de crianças e adolescentes na população total - Maranhão, Nordeste e Brasil, 2010

\begin{tabular}{c|c|c|c}
\hline Âmbito & População total & População na faixa etária de 0 a 19 anos & Proporção (\%) \\
\hline Maranhão & 6.574 .789 & 2.717 .736 & $41,3 \%$ \\
\hline Nordeste & 53.081 .950 & 19.241 .822 & $36,3 \%$ \\
\hline Brasil & 190.732 .694 & 62.923 .165 & $33,0 \%$ \\
\hline
\end{tabular}

Fonte: INSTITUTO BRASILEIRO DE GEOGRAFIA E ESTATÍSTICA. Censo Demográfico 2010: características da população e dos domicílios: resultados do universo. Rio de Janeiro, 2011. Disponivel em:<http://www.ibge.gov.br/home/estatistica/população/ censo2010/default.shtm>. Acesso em: 21 maio 2013. 
Tabela 3 - Taxa de Urbanização - Maranhão, Nordeste e Brasil, 2010

\begin{tabular}{c|c|c|c}
\hline Âmbito & População total & População urbana & Taxa de urbanização (\%) \\
\hline Maranhão & 6.574 .789 & 4.147 .149 & $63,1 \%$ \\
\hline Nordeste & 53.081 .950 & 38.821 .246 & $73,1 \%$ \\
\hline Brasil & 190.732 .694 & 160.925 .792 & $84,4 \%$ \\
\hline
\end{tabular}

Fonte: IBGE (2010).

renda até R\$ 140,00. O Benefício de Prestação Continuada da Assistência Social beneficia pessoas idosas e pessoas com deficiências com rendimento domiciliar per capita inferior a $1 \frac{1}{4}$ de salário mínimo. 0 Cadastro Único para Programas Sociais do governo federal adota o valor referencial de $1 / 2$ salário mínimo per capita para a inclusão de famílias no CadÚnico.

No entanto, independente de qual critério seja utilizado, o Maranhão mantinha-se, no ano de 2010, nas piores posições em termos dos indicadores de pobreza e extrema pobreza no país.

Em 2014, o estudo da World Without Poverty (WWP), em conjunto com o IPEA, considerou pobres de renda aqueles que ganham até $R \$ 140$ mensais. 0 valor é maior do que a linha de extrema pobreza brasileira, de $R \$ 77$ mensais (equivalente a US $\$ 1,25$ diário). Se a pobreza crônica considerasse apenas a população em situação de miséria, o percentual da redução seria ainda menor do que $01,6 \%$ da população, identificado pelos autores do trabalho1.

Se considerado o critério de renda per capita, o Estado ocupava a última posição do ranking nacional em termos de população em situação de extrema pobreza no país, com $26,3 \%$ da população sobrevivendo com uma renda per capita mensal inferior a $\mathrm{R} \$ 70,00$ (setenta reais), conforme o IBGE (2010). Esse percentual correspondia a 1.729 .170 pessoas nessas condições. Esse dado revela a violência estrutural que assola milhões de famílias no Estado, que não conseguem assegurar as mínimas condições de sobrevivência e cujo futuro já está comprometido desde o nascimento. A Tabela 4 mostra o ranking da extrema pobreza no Brasil em 2010.
Utilizando a mesma base de dados, 0 percentual eleva-se para $63 \%$, se for considerado 0 critério utilizado para inclusão no CadÚnico, o que corresponderia a mais de 4 milhões de pessoas na condição de pobreza ou extrema pobreza no estado.

Os dados do IBGE demonstram ainda que 32 (trinta e dois) dos 50 (cinquenta) municípios mais pobres do país situavam-se no estado do Maranhão em 2010, sendo que o município com menor renda per capita naquele ano era Belágua/MA, com valor equivalente a $\mathrm{R} \$ 147,70$ (INSTITUTO BRASILEIRO DE GEOGRAFIA E ESTATÍSTICA, 2010).

A despeito de o Produto Interno Bruto (PIB) do Maranhão ocupar, em 2010, a $16^{a}$ posição entre os 27 estados brasileiros, incluindo o Distrito Federal, o indicador relativo à renda média per capita colocava o estado também na última posição, com 0 valor de $R \$ 1.274,00$, enquanto o Nordeste possuia rendimento médio mensal na ordem de $R \$ 1.452,00 \mathrm{e}$ o Brasil alcançava o valor de R\$2.222,00 (INSTITUTO BRASILEIRO DE GEOGRAFIA E ESTATÍSTICA, 2010). Decerto essa situação tem relação com a elevada concentração de renda no estado.

Os dados relativos a rendimento do trabalho também são ilustrativos da situação de pobreza em que vive a maioria da população maranhense. Dados do Censo 2010 do IBGE mostram que, em agosto de 2010, o Maranhão possuía 2.585 .059 pessoas economicamente ativas, onde 2.361 .385 estavam ocupadas e 223.674 desocupadas, gerando uma taxa de desocupação de $8,7 \%$. O valor do rendimento médio mensal das pessoas ocupadas era de $R \$ 747,32$. Entre os homens o rendimento era de $R \$ 901,45$ e entre as mulheres de $R \$ 601,64$, apontando uma diferença de 49,8\% maior para os homens (INSTITUTOBRASILEIRO DE GEOGRAFIA E ESTATÍSTICA, 2010). 
Tabela 4 - Unidades federativas por incidência da pobreza - Brasil, 2010

\begin{tabular}{|c|c|c|}
\hline Posição & Estado & Proporção (\%) \\
\hline 1 & Santa Catarina & 1,7 \\
\hline 2 & Distrito Federal & 1,9 \\
\hline 3 & São Paulo & 2,7 \\
\hline 4 & Rio Grande do Sul & 2,9 \\
\hline 5 & Paraná & 3,0 \\
\hline 6 & Goiás & 3,7 \\
\hline 7 & Rio de Janeiro & 3,9 \\
\hline 8 & Espírito Santo & 4,3 \\
\hline 9 & Minas Gerais & 4,7 \\
\hline 10 & Mato Grosso do Sul & 5,0 \\
\hline 11 & Mato Grosso & 5,9 \\
\hline 12 & Rondônia & 7,9 \\
\hline 13 & Tocantins & 11,9 \\
\hline 14 & Amapá & 12,8 \\
\hline 15 & Rio Grande do Norte & 13,0 \\
\hline 16 & Sergipe & 15,3 \\
\hline 17 & Pernambuco & 16,1 \\
\hline 18 & Paraíba & 16,3 \\
\hline 19 & Bahia & 17,7 \\
\hline 20 & Roraima & 17,9 \\
\hline 21 & Ceará & 18,4 \\
\hline 22 & Acre & 18,9 \\
\hline 23 & Pará & 19,2 \\
\hline 24 & Amazonas & 19,3 \\
\hline 25 & Alagoas & 20,5 \\
\hline 26 & Piauí & 21,6 \\
\hline 27 & Maranhão & 26,3 \\
\hline
\end{tabular}

Fonte: IBGE (2010).

Os dados mostram ainda que, das pessoas ocupadas, $18,9 \%$ não tinham rendimentos e $68,8 \%$ ganhavam até um salário mínimo por mês. Ainda que esse percentual reflita uma pequena melhora em relação ao que foi identificado em 2005, que era de $73 \%$, essa situação indica que a maioria das famílias maranhenses encontrava-se em condição de pobreza ou pobreza extrema.

Asituação de pobreza no estado é agravada pela ausência dos serviços públicos. O Censo 2010 do IBGE apontou, por exemplo, que quase $90 \%$ dos municípios maranhenses possuíam abaixo de $5 \%$ de cobertura de rede de esgoto (INSTITUTO BRASILEIRO DE GEOGRAFIA E ESTATÍSTICA, 2010).

\section{DESENVOLVIMENTO HUMANO NO MARANHÃO}

Os indicadores socioeconômicos do Maranhão influenciam fortemente a posição do estado no ranking do Índice de Desenvolvimento Humano (IDH). O Índice de Desenvolvimento Humano (IDH) é um dado utilizado pela Organização das Nações Unidas (ONU) para analisar a qualidade de vida de uma determinada população. $O$ ranking dos estados em relação ao IDH desmonstra a disparidade no desenvolvimento regional, pois enquanto os estados das regiões Sul e Sudeste possuem os melhores índices, os do Nordeste ocupam as piores posições. 
Tabela 5 - Índice de Desenvolvimento Humano - Maranhão, Nordeste e Brasil, 2006 a 2010

\begin{tabular}{l|c|c|c|c|c}
\hline Local & $\mathbf{2 0 0 6}$ & $\mathbf{2 0 0 7}$ & $\mathbf{2 0 0 8}$ & $\mathbf{2 0 0 9}$ & $\mathbf{2 0 1 0}$ \\
\hline Maranhão & 0,707 & 0,724 & 0,683 & 0,724 & 0,683 \\
\hline Nordeste & 0,733 & 0,749 & & & 0,608 \\
\hline Brasil & 0,803 & 0,816 & 0,807 & 0,693 & 0,699 \\
\hline
\end{tabular}

Fonte: PROGRAMA DAS NAÇÕES UNIDAS PARA O DESENVOLVIMENTO. Relatório de Desenvolvimento Humano Brasil 2009/2010: valores e desenvolvimento humano. Brasília, DF, 2010. Disponível em:<www.pnud.org.br>. Acesso em: 28 set. 2014

Em função de uma mudança, ocorrida em 2010, na metodologia adotada pelo PNUD/ONU, que é a organização responsável por esse cálculo, não é adequado comparar a evolução nominal desse índice, mas interessa verificar que o posicionamento do estado no ranking nacional pouco variou entre 2005 e 2010.

Em 2010, segundo o PNUD, o Maranhão alcançou o índice de 0,683 , situando-se na $26^{2}$ posição entre as unidades da Federação. Comparativamente a 2005, o estado oscilou uma posição para melhor (PROGRAMA DAS NAÇÕES UNIDAS PARA O DESENVOLVIMENTO, 2010). Os dados referentes ao Maranhão, comparativamente à região Nordeste e ao Brasil, no período entre 2006 e 2010, encontramse na Tabela 5.

\section{A ESTRUTURAÇÃO DA POLÍTICA DE ASSISTÊNCIA SOCIAL NO MARANHÃO}

Esse item será analisado a partir das diretrizes estabelecidas pela Lei Orgânica da Assistência Social (LOAS), que estabeleceu a necessidade de reformulação da assistência social, via descentralização das ações pelos estados, municípios e Distrito Federal e conferiu ao Estado a responsabilidade central no desenvolvimento da política social com a exigência de comando único em cada esfera de governo. Na esteira da Constituição Federal de 1988, a LOAS introduziu vários mecanismos de participação na formulação e controle das políticas de Assistência Social, a exemplo de que os planos de assistência social em todas as esferas, desde então, devem ser elaborados em consonância com as diretrizes definidas pelo Conselho Nacional de Assistência Social (CNAS).
Além das inovações na esfera federal, consolidadas por meio de resoluções do CNAS, como a regulamentação da Política Nacional de Assistência Social (PNAS/2004), da Norma Operacional Básica do Sistema Único de Assistência Social (NOB/SUAS/2005) e da Norma Operacional Básica de Recursos Humanos do SUAS (NOB/RH/ SUAS/2007), os gestores públicos devem considerar outras referências que foram instituídas nesse período para normatizar 0 atendimento aos direitos de crianças e adolescentes, a exemplo do Plano Nacional de Promoção, Proteção e Defesa do Direito de Crianças e Adolescentes à Convivência Familiar e Comunitária (PNCFC/2006) e do Sistema Nacional de Atendimento Socioeducativo (SINASE/2006), que foi criado por meio de Resolução do Conselho Nacional dos Direitos de Crianças e Adolescentes (CONANDA). Posteriormente, foi formalizado por meio da Lei $n^{\circ}$ 12.594, de 18 de janeiro de 2012

Esses vários instrumentos consolidaram outra sistemática de estruturação da política de assistência social, com adoção de dois níveis de proteção: a Proteção Social Básica e a Proteção Social Especial, o que repercutiu ainda em uma nova tipificação dos serviços socioassistenciais. A Tipificação Nacional de Serviços Socioassistenciais foi aprovada pela Resolução CNAS no 109, de 11 de novembro de 2009.

Ainda que os entes públicos fossem adotando, progressivamente, essas mudanças, 0 período de 2006 a 2010 registra uma grande mudança na organização da política de assistência social no Estado do Maranhão. As inovações ocorridas no plano federal repercutiram no estado, com a adequação do órgão gestor estadual, que passou a adotar uma estrutura condizente com aquelas 
normas, bem como assumiu o comando único da política de Assistência Social, através do Decreto Estadual $n^{0} 22.908$, de 02 de janeiro de 2007. A partir desse ano, a SEDES passou a organizar sua atuação por meio de várias superintendências que incorporaram as denominações previstas no SUAS: Gestão do SUAS, Proteção Social Básica, Proteção Social Especial e Gestão das Ações de Segurança Alimentar e Nutricional, dado que essa última política também estava sob o comando da SEDES na ocasião. Em 2012, uma reforma administrativa promovida pelo governo estadual vinculou a política de Assistência Social à área de Direitos Humanos, criando a Secretaria de Estado dos Direitos Humanos, da Assistência Social e da Cidadania (SEDIHC).

Além da modificação na estrutura interna, a SEDES também alterou a lógica da política de atendimento aos direitos de crianças e adolescentes. A partir de 2007, o órgão gestor estadual assumiu a coordenação e implementação do atendimento socioeducativo, por meio da FUNAC/MA, que redefiniu o foco de sua missão para a implementação das medidas socioeducativas privativas e restritivas de liberdade, ao mesmo tempo em que assumiu a função de estimular e acompanhar o processo de municipalização do atendimento socioeducativo em meio aberto.

As linhas de ação da FUNAC/MA concentraram-se, desde então, em: a) Atendimento inicial, prestado no Complexo Integrado de Proteção à Criança e ao Adolescente; b) Internação masculina e feminina; c) Internação provisória masculina e feminina; e Semiliberdade masculina e feminina.

A perspectiva de descentralização políticoadministrativa, trazida pela Constituição Federal e pelas normativas decorrentes da mesma, ganhou densidade no Maranhão no período de 2007 a 2009, por meio de vários programas que apoiaram os municípios na implementação de projetos e medidas associadas às novas orientações da PNAS e do SUAS.

Um desdobramento da celebração do Pacto de Aprimoramento da Gestão foi o Incentivo
Financeiro ao Aprimoramento da Gestão (IGE), com vistas a potencializar a execução das prioridades apontadas no referido documento. 0 Termo foi assinado em 10 de outubro de 2007, entre o Ministério de Desenvolvimento Social e o Governo do Estado do Maranhão e publicado através das Portarias 350 e 351, de 03 de outubro de 2007, do MDS, conforme consta no Relatório de Gestão da SEDES (MARANHÃO, 2010b).

\subsection{A cobertura dos serviços e benefícios socioassistenciais}

A partir da constituição do SUAS, as ações da Assistência Social passaram a ser articuladas em dois tipos de proteção social: a) Proteção Social Básica, e b) Proteção Social Especial.

Além disso, o SUAS estabelece a oferta de Benefícios Assistenciais que são prestados a públicos específicos, articulada aos serviços.

\subsubsection{Os serviços de Proteção Social Básica}

Os serviços de Proteção Social Básica buscam 0 desenvolvimento de potencialidades e 0 fortalecimento de vínculos familiares e comunitários. Incluem o desenvolvimento de serviços, programas e projetos locais de acolhimento, convivência e socialização de famílias e de indivíduos, a partir da situação de vulnerabilidade constatada.

A principal unidade responsável por esses serviços é o Centro de Referência de Assistência Social (CRAS), em virtude de sua capilaridade no território, como porta de entrada nas áreas de vulnerabilidade e risco social.

Em 2010, identificou-se um total de 6.801 CRAS em todo o território nacional, distribuídos em 4.720 municípios, o que representa $84,8 \%$ de cobertura dos 5.565 municípios brasileiros. No Maranhão, o número de CRAS atingiu o quantitativo de 292 unidades em 2010, com crescimento de 135\% em relação ao ano de 2005.

O principal serviço na Proteção Social Básica é o Programa de Proteção e Atendimento 
Integral à Família (PAIF), cuja execução é obrigatória e exclusiva pelo CRAS.

O Serviço de Convivência e Fortalecimento de Vínculos para Adolescentes e Jovens de 15 a 17 anos é também denominado como Projovem Adolescente.

\subsubsection{Os Serviços de Proteção Social Especial}

O SUAS define a Proteção Social Especial como o nível de proteção responsável pela oferta de serviços, programas e projetos de caráter especializado, que requerem estruturação técnica e operativa específicas. A Proteção Social Especial está classificada em Média Complexidade e Alta Complexidade.

Os serviços de Média Complexidade destinam-se a famílias e indivíduos com seus direitos violados cujos vínculos familiar e comunitário não foram rompidos. São divididos em conformidade com o público.

Os serviços de Alta Complexidade oferecem atendimento às famílias e indivíduos que se encontram em situação de abandono, ameaça ou violação de direitos, necessitando de acolhimento provisório, fora de seu núcleo familiar de origem.

A principal unidade responsável por esses serviços é o Centro de Referência Especializado de Assistência Social (CREAS), como unidade pública de atendimento e referência para o acompanhamento especializado e continuado a famílias e indivíduos em situação de ameaça ou violação de direitos.

O Censo SUAS 2010 cadastrou 1.540 CREAS municipais e 50 CREAS regionais, em todo 0 país. Registra-se a expansão significativa da rede de CREAS no Estado do Maranhão, com praticamente $90 \%$ a mais que a existente em 2009, alcançando o percentual de $42,9 \%$ de cobertura dos municípios.

0 atendimento do PAEFI envolve, segundo o CENSO SUAS 2010, diversas situações de vulnerabilidade social, a exemplo de: a) violência física; b) Violência psicológica; c) Abuso sexual; d) Exploração sexual; e) Negligência ou abandono; f) Tráfico de pessoas; g) Trabalho infantil; h) Situação de rua; i) Discriminação em decorrência da orientação sexual; j) Discriminação em decorrência da raçal etnia.

Os dados disponíveis nos relatórios de gestão dos órgãos diretamente responsáveis pelo desenvolvimento dos serviços de proteção social especial demonstram que persiste a omissão e/ou negligência do Estado e da sociedade em relação à proteção dos direitos das crianças e dos adolescentes.

Em 2010, as situações de violência física e psicológica somadas chegam a 174 casos contra crianças e dos adolescentes; abusos sexuais correspondem 91 casos seguidos de exploração sexual, com 87 casos, negligência e trabalho infantil, cada situação com 85 casos (Tabela 6).

Uma análise dos dados disponíveis em relação ao perfil das vítimas mostra que a maioria constitui-se de meninas, exceto os casos de discriminação por orientação sexual ou por raça e etnia, conforme a Tabela 7.

É necessário lançar um olhar mais apurado sobre esses números e perceber que eles não conseguem revelar toda a realidade. Os quantitativos informados em cada município são pequenos, o que pode nos levar à sensação de que os índices dessas violências são baixos, correndo-se o risco de acharmos que tivemos avanços.

\subsubsection{A cobertura dos programas de transferência de renda}

O principal programa de transferência direta de renda com condicionalidades, a partir de 2004, é o Programa Bolsa Família (PBF), instituído pelo Governo Federal e que se configura como um programa que beneficia famílias pobres e extremamente pobres. Em sua constituição, o PBF integrava o Programa Fome Zero.

Em 2010, o Programa Bolsa Família, no Maranhão, alcançou o número de 856.454 famílias participantes (CEF, 2010 apud MARANHÃO, 2010b), o que representou um crescimento de $57,4 \% \mathrm{em}$ relação a 2005. A estimativa de famílias de baixa renda, segundo o Perfil Cadastro Único, era da 
Tabela 6 - Crianças e adolescentes vítimas de violência - Maranhão, 2010

\begin{tabular}{l|c|c}
\hline \multicolumn{1}{c|}{ Tipo de violência } & $\begin{array}{c}\text { Quantidade } \\
\text { de casos }\end{array}$ & $\begin{array}{c}\text { Quantidade de crianças e } \\
\text { adolescentes }\end{array}$ \\
\hline Violência física & 219 & 85 \\
\hline Violência psicológica & 224 & 89 \\
\hline Abuso sexual & 150 & 91 \\
\hline Exploração sexual & 130 & 87 \\
\hline Negligência ou abandono & 156 & 85 \\
\hline Tráfico & 80 & 13 \\
\hline Trabalho infantil & 87 & 87 \\
\hline Situação de rua & 157 & 45 \\
\hline Discriminação por orientação sexual & 132 & 31 \\
\hline Discriminação por raça e etnia & 128 & 19 \\
\hline Famílias com crianças e adolescentes afastados do vínculo familiar & 35 & 70 \\
\hline Famílias com descumprimento de condicionalidade do PBF e PETI & 66 & 84 \\
em decorrência de violação de direitos & & \\
\hline TOTAL & 1.564 & 786 \\
\hline
\end{tabular}

Fonte: BRASIL. Ministério do Desenvolvimento Social e Combate à Fome. Censo SUAS 2010. Brasília, DF, 2011. Disponível em:<http://aplicacoes.mds.gov.br>. Acesso em: 28 set. 2014.

Tabela 7 - Perfil das crianças e adolescentes vítimas de violência - Maranhão, 2010

\begin{tabular}{l|c|c|c|c|c}
\hline \multirow{2}{*}{ Tipo de violência } & \multicolumn{5}{c}{ Quantidade de crianças e adolescentes envolvidos } \\
\cline { 2 - 6 } & Total & Meninos & $\%$ & Meninas & $\%$ \\
\hline Violência física & 85 & 34 & $40,0 \%$ & 51 & $60,0 \%$ \\
\hline Violência psicológica & 89 & 27 & $30,3 \%$ & 62 & $69,7 \%$ \\
\hline Abuso sexual & 91 & 18 & $19,8 \%$ & 73 & $80,2 \%$ \\
\hline Exploração sexual & 87 & 21 & $24,1 \%$ & 66 & $75,9 \%$ \\
\hline Negligência ou abandono & 85 & 35 & $41,2 \%$ & 50 & $58,8 \%$ \\
\hline Tráfico & 13 & 04 & $30,8 \%$ & 09 & $69,2 \%$ \\
\hline Trabalho infantil & 87 & 36 & $41,4 \%$ & 51 & $58,6 \%$ \\
\hline Situação de rua & 45 & 20 & $44,4 \%$ & 25 & $55,6 \%$ \\
\hline Discriminação por orientação sexual & 31 & 29 & $93,5 \%$ & 02 & $6,5 \%$ \\
\hline Discriminação por raça e etnia & 19 & 13 & $68,4 \%$ & 06 & $31,6 \%$ \\
\hline TOTAL & 786 & 335 & $\mathbf{4 2 , 6 \%}$ & $\mathbf{4 5 1}$ & $\mathbf{5 7 , 4 \%}$ \\
\hline
\end{tabular}

Fonte: (BRASIL, 2010).

ordem de 1.075 .986 famílias, enquanto a estimativa de famílias pobres, de acordo com o Perfil Bolsa Família, alcançava apenas 859.489 famílias. Dessa forma, 216.497 deixaram de ser atendidas pelo Programa. $O$ número de participantes no PBF em 2010 estava bem próximo do número de famílias identificado com o critério do Perfil Bolsa Família, mas representa apenas $80 \%$ do número calculado pelo Perfil Cadastro Único, portanto, $20 \%$ das famílias pobres deixaram de ser atendidas. Outro programa significativo de transferência direta de renda com condicionalidades é o Programa de Erradicação do Trabalho Infantil (PETI), que compõe o SUAS e que articula um conjunto de ações que visa retirar crianças e adolescentes com idade inferior a 16 anos da exploração do trabalho precoce.

O Censo 2010 do IBGE identificou cerca de 144 mil crianças e adolescentes na faixa etária entre 10 e 17 anos trabalhando no Maranhão. Desse total, quase 61 mil tinham idade entre 10 e 14 anos e perto de 83 mil estavam na faixa etária entre 15 e 17 anos (INSTITUTO BRASILEIRO DE GEOGRAFIA E ESTATÍSTICA, 2010).

O Censo 2010 mostrou que cerca de 76 mil crianças e adolescentes, entre 10 e 17 anos, trabalhavam em atividades agrícolas e que um contingente de cerca de 22 mil meninos e meninas foram identificados no serviço urbano. $E$ também apontou a existência de 12 mil crianças e 
adolescentes realizando serviços domésticos no Estado do Maranhão (INSTITUTO BRASILEIRO DE GEOGRAFIA E ESTATÍSTICA, 2010).

\subsubsection{A cobertura dos serviços de proteção especial a crianças e adolescentes}

O Estatuto da Criança e do Adolescente (ECA) prevê no seu art. 101, I a IV d, que à criança ou ao adolescente em conflito com a lei, serão aplicadas medidas socioeducativas, como: Advertência, Obrigação de Reparar o Dano, Prestação de Serviços à Comunidade, Liberdade Assistida, Semiliberdade, Internação em Estabelecimento Educacional ou medidas de proteção (BRASIL, 1990).

As medidas socioeducativas, de natureza sancionadora e com finalidade pedagógica, devem ser aplicadas e operadas conforme o grau e com as características da infração, circunstâncias sociofamiliares e disponibilidade de programas e serviços em nível municipal, regional e estadual.

A estrutura da FUNAC/MA inclui: em São Luís, três Unidades de Internação, sendo duas com atendimento aos adolescentes do sexo masculino (Centro da Juventude Esperança e Centro da Juventude Renascer) e uma com atendimento dirigido às meninas (Centro da Juventude Florescer), uma Unidade de Semiliberdade masculina (Centro da Juventude Nova Jerusalém), uma Unidade de Internação Provisória (Centro da Juventude Canaã), um Programa de Liberdade assistida, atendimento Inicial no Centro Integrado e um Programa de atendimento aos Egressos e, em Imperatriz, uma Unidade de Internação Provisória (Centro da Juventude Semear) e uma Unidade de Semiliberdade (Centro da Juventude Cidadã).

A Tabela 8 mostra a evolução do número de adolescentes no período de 2006 a 2010 atendidos pelo conjunto das unidades, com exceção do atendimento inicial prestado pela unidade inserida no Complexo Integrado de Proteção às Crianças e aos Adolescentes, que é detalhado mais adiante.

\subsubsection{Atendimento inicial}

Os dados sobre 0 atendimento inicial durante 0 ano de 2010 indicam que foram atendidos 347 adolescentes a quem se atribui autoria de ato infracional, significando um aumento de $11,5 \% \mathrm{em}$ relação ao ano de 2009. Do total de atendidos em 2010, 344 são do sexo masculino e 03 do sexo feminino.

Os dados sobre a faixa etária mostram que a maioria absoluta dos adolescentes encontra-se na faixa etária dos 16 aos 18 anos (73\%).

Quanto ao tipo de ato infracional praticado, sobressai-se a prática de roubo $(48 \%)$, seguido de tentativa, acusação e ou participação em roubo $(13 \%)$, tráfico de drogas $(7 \%)$ e porte ilegal de armas (5\%).

Tabela 8 - Adolescentes atendidos pela FUNAC/MA, 2006 a 2010

\begin{tabular}{|c|c|c|c|c|c|c|}
\hline \multirow[t]{2}{*}{$\mathrm{N}^{0}$} & \multirow[t]{2}{*}{ Unidades de atendimento } & \multicolumn{5}{|c|}{$\mathrm{N}^{0}$ de adolescentes atendidos } \\
\hline & & 2006 & 2007 & 2008 & 2009 & 2010 \\
\hline \multicolumn{7}{|c|}{ SÃO LUIS } \\
\hline 01 & Centro da Juventude Canaã (CJC) & 170 & 216 & 259 & 237 & 269 \\
\hline 02 & Centro da Juventude Esperança (CJE) & 163 & 145 & 108 & 152 & 132 \\
\hline 03 & Centro da Juventude Florescer (CJF) & 14 & 13 & 09 & 18 & 15 \\
\hline 04 & Centro da Juventude Nova Jerusalém (CJNJ) & 30 & 38 & 39 & 37 & 36 \\
\hline \multicolumn{7}{|c|}{ IMPERATRIZ } \\
\hline 05 & Centro da Juventude Semear (CJS) & 87 & 112 & 124 & 117 & 138 \\
\hline 06 & Centro da Juventude Cidadã (CJCid) & 14 & 15 & 23 & 17 & 20 \\
\hline \multicolumn{2}{|c|}{ TOTAL } & 478 & 539 & 562 & 578 & 610 \\
\hline
\end{tabular}

Fonte: MARANHÃO. Secretaria de Direitos Humanos, Assistência Social e Cidadania. Fundação da Criança e do Adolescente. Relatório de Gestão do SUAS. São Luís, 2006; MARANHÃO. Secretaria de Direitos Humanos, Assistência Social e Cidadania. Fundação da Criança e do Adolescente. Relatório de Gestão do SUAS. São Luís, 2007; MARANHÃO. Secretaria de Direitos Humanos, Assistência Social e Cidadania. Fundação da Criança e do Adolescente. Relatório de Gestão do SUAS. São Luís, 2008; MARANHÃO. Secretaria de Direitos Humanos, Assistência Social e Cidadania. Fundação da Criança e do Adolescente. Relatório de Gestão do SUAS. São Luís, 2009; MARANHÃO. Secretaria de Direitos Humanos, Assistência Social e Cidadania. Fundação da Criança e do Adolescente. Relatório de Gestão do SUAS. São Luís, 2010a. 
A maioria dos adolescentes atendidos em 2010 praticou ato infracional pela primeira vez. $O$ percentual dos que reiteraram alcança $21,6 \%$. Foi registrado apenas um caso de fuga. Considerando a procedência desses adolescentes, $87,6 \%$ são oriundos da capital do Estado.

Outra linha de ação da FUNAC/MA é o acompanhamento aos adolescentes com medida protetiva, que se dá por meio de atendimento e acompanhamento social aos adolescentes submetidos às medidas protetivas descritas no artigo 101 do ECA, encaminhados pelo Juizado da Infância e Juventude, atendimento social às famílias dos adolescentes em cumprimento de medida protetiva e acompanhamento pedagógico.

\subsubsection{Atendimento de Internação Provisória}

A medida cautelar de internação provisória está prevista no artigo 108, parágrafo único do ECA

[...] a internação antes da sentença, pode ser determinada pelo prazo máximo de quarenta e cinco dias e sua decisão deverá ser fundamentada e basear-se em indícios suficientes de autoria e materialidade, demonstrada a necessidade imperiosa da medida. (BRASIL, 1990).

As atividades realizadas nas unidades de internação provisória envolvem atendimento psicológico, social, pedagógico e jurídico, a escolarização, as oficinas e qualificação profissional, o atendimento à saúde, as atividades de esporte, cultura e lazer e a assistência religiosa.

O relatório de gestão da FUNAC/MA 2010 aponta vários problemas relacionados às condições de habitabilidade das duas unidades de internação provisória (MARANHÃO, 2010a). O Centro Canaã tem necessidade de melhorias e reparos nas instalações elétricas, hidráulicas, instalações sanitárias e nos alojamentos dos adolescentes. Além disso, essa unidade não possui auditório e a sala de monitoria é inadequada. O Centro Semear não dispõe de condições adequadas de salubridade nos alojamentos em decorrência de problemas hidráulicos, os dormitórios não têm ventilação adequada e os colchões precisam ser substituídos. Há problemas nos banheiros, causando intranquilidade $\mathrm{e}$ desconforto aos adolescentes. Também se destacava a necessidade de melhorias nos espaços reservados para a profissionalização, escolares, esportivas e atendimentos individuais.

A execução da medida de internação provisória é realizada pelas unidades Centro da Juventude Canaã, localizada em São Luís, e Centro da Juventude Semear, em Imperatriz/MA, onde se registrou, no ano de 2010, um total de 407 adolescentes atendidos, representando um aumento de $13 \%$ em comparação a 2009. Destes, 269 adolescentes foram atendidos no Canaã e 138 no Semear, todos do sexo masculino, na faixa etária de 12 aos 18 anos incompletos.

O Centro da Juventude Canaã atende adolescentes de todo o estado do Maranhão, exceto da Região Tocantina, cuja cobertura é realizada pelo Centro da Juventude Semear. No ano de 2010, $57 \%$ dos adolescentes atendidos no Canaã eram provenientes da Capital do Estado e $43 \%$ oriundos do interior do Maranhão (Tabela 9).

Com relação à situação dos adolescentes, quando da aplicação da medida de internação provisória, registra-se que no Centro da Juventude Canaã $87 \%$ dos adolescentes eram de primeira medida e $13 \%$ estavam em reiteração. Já o Semear registrou apenas $41 \%$ como primeira medida. Os demais estavam em reiteração (28\%); em descumprimento de medida (25\%) ou já estavam cumprindo medida anteriormente imposta (6\%), conforme Relatório de Gestão da FUNAC-MA (2010). A maioria dos adolescentes (55\%) é desligada das unidades em função da revogação da medida. Foram registradas 16 fugas na unidade Semear (MARANHÃO, 2010a).

Aprocedência dos adolescentes internados no Centro da Juventude Canaã foi da ordem de $57 \%$ da capital e $43 \%$ de outros municípios do estado. 
Tabela 9 - Adolescentes com internação provisória - Maranhão, 2010

\begin{tabular}{l|c|c|c}
\hline \multicolumn{1}{c|}{ Unidade } & Capital & Interior & Total \\
\hline Centro da Juventude Canaã & 154 & 115 & 269 \\
\hline Centro da Juventude Semear & 98 & 98 & 138 \\
\hline Total & $\mathbf{2 5 2}$ & $\mathbf{2 1 3}$ & $\mathbf{4 0 7}$ \\
\hline
\end{tabular}

Fonte: (MARANHÃO, 2010a).

Quanto à faixa etária, há predominância no Estado da faixa etária dos 16 aos 18 anos (75,6\%). Isoladamente, os casos no Centro da Juventude Canaã atingem $77,6 \%$ nessa faixa etária.

Quanto ao tipo de ato infracional praticado, sobressai-se no estado a prática de roubo (54\%), seguido de homicídio (14\%), furto (6\%) e tentativa de homicídio (5\%). No Centro da Juventude Canaã destacam-se os casos de roubo (52\%), homicídio $(16 \%)$ e tentativa de homicídio (8\%) e no Centro da Juventude Semear destacam-se os casos de roubo $(54 \%)$, homicídio (10\%) e furto $(7 \%)$.

\subsubsection{Atendimento de Semiliberdade}

A execução da medida de semiliberdade está prevista no artigo 120 do $E C A$, não comporta prazo e pode ser determinada desde o início ou como forma de transição da internação para o meio aberto. Possibilita a realização de atividades externas independentes de autorização judicial.

As atividades realizadas nas unidades de semiliberdade também envolvem atendimento psicológico, social, pedagógico e jurídico, a escolarização, as oficinas e qualificação profissional, o atendimento à saúde, as atividades de esporte, cultura e lazer e a assistência religiosa.

Esse atendimento é realizado pela FUNAC/MA nas unidades Centro da Juventude Nova Jerusalém, localizado em São Luís, e Centro da Juventude Cidadã, em Imperatriz/MA. Essas unidades possuem capacidade para atender respectivamente 14 e 16 adolescentes, de forma simultânea. Registrase no ano de 2010, que as unidades atenderam um total de 56 adolescentes, sendo 36 na unidade Nova Jerusalém e 20 no Centro da Juventude Cidadã.

O relatório de gestão da FUNAC/MA 2010 aponta que as instalações do Centro da Juventude
Nova Jerusalém são insalubres, inadequadas, pois não possui número de acomodações suficientes que permita a separação dos internos de primeira e segunda medida (MARANHÃO, 2010a). Quanto ao Centro de Semiliberdade de Imperatriz o relatório destaca que, no ano de 2010, obteve avanços na estrutura física da Unidade.

Apenas 3 casos relacionaram-se a reiteração, porém registraram-se 16 fugas nas duas unidades. $47 \%$ dos casos registrados na Unidade Nova Jerusalém foram oriundos da capital do estado e $53 \%$ dos outros municípios.

Quanto ao tipo de ato infracional praticado, sobressai-se no Estado a prática de roubo (54\%), seguido de homicídio (14\%), furto $(6 \%)$ e tentativa de homicídio (5\%). No Centro da Juventude Canaã destacam-se os casos de roubo (38\%), homicídio $(29 \%)$ e latrocínio $(21 \%)$.

\subsubsection{Atendimento de Internação}

A internação em estabelecimento educacional está prevista no artigo 112 do ECA e se constitui uma medida privativa de liberdade, sujeita aos princípios da brevidade, excepcionalidade e respeito à condição peculiar de pessoa em desenvolvimento. Não comporta prazo determinado, devendo ser reavaliada no máximo a cada seis meses. Contudo, não pode ultrapassar o período de três anos.

Para execução da internação, a FUNACl MA dispõe das unidades Centro da Juventude Esperança, localizada no município de São José de Ribamar, e da Unidade Feminina Centro da Juventude Florescer, em São Luís. Quando necessário, esta última atende também adolescentes com medida de internação provisória e semiliberdade, em razão do Estado do Maranhão não possuir unidade específica 
para essa finalidade. A capacidade das unidades é de 40 adolescentes no Centro da Juventude Esperança e 10 adolescentes no Florescer. A Unidade de Internação encontra-se interditada em virtude de ação do Ministério Público Estadual por encontrar-se em desacordo com os preceitos do ECA.

As unidades têm a obrigatoriedade de assegurar aos adolescentes internos atendimento técnico especializado - social, psicológico, jurídico, terapêutico e pedagógico; atender suas necessidades básicas de higiene pessoal, alimentação, vestuário, medicamentos; atendimento de saúde; escolarização, profissionalização; atividades esportivas, de cultura e lazer, além de assegurar instalações físicas em condições adequadas de habitabilidade, higiene, salubridade e segurança.

Entre os pontos positivos destacados no Relatório de gestão FUNAC 2010 estão a integração e coesão da equipe e a percepção do processo evolutivo dos adolescentes por meio do acompanhamento nas atividades internas e externas e participação dos socioeducadores nos estudos de caso. Também foi ressaltada a contratação de novos servidores seguindo critérios estabelecidos sobre 0 perfil profissional (MARANHÃO, 2010a). A redução de conflitos internos entre os adolescentes contribuiu para a melhoria no cumprimento das medidas.

O relatório mencionou vários aspectos dificultadores no atendimento da internação no Centro da Juventude Esperança, a exemplo de: falta de cumprimento pelo corpo funcional e pelos adolescentes dos procedimentos e das diretrizes contidas no Regimento Interno, bem como nos manuais do adolescente e servidor; inexistência de espaços adequados para hospedagem dos familiares quando da visita aos filhos; servidores que são devolvidos para a sede por conduta inadequada e que são devolvidos à Unidade, enfraquecendo a direção diante de resoluções que incluem a segurança do Centro; fluxo diário de novos servidores sem preparação e conhecimento da Direção; falta de materiais para a efetivação da oficina de cerâmica; pouca consistência na comunicação da Escola Sete de Setembro com o Centro; diminuição do quadro de socioeducadores de 12 para 08 ; falta de espaço físico apropriado para a realização da atividade do Hip-Hop, bem como aparelho de som; insuficiência do número de professores da escola Sete de Setembro e falta de material esportivo e de lazer para as atividades. Em 2010, foram atendidos 147 adolescentes, sendo 132 adolescentes do sexo masculino e 15 do sexo feminino (Tabela 10). Registrou-se uma redução no atendimento do Centro da Juventude Esperança em $13 \%$ em comparação a 2009, que pode ser justificado pelo processo de intervenção sofrida pela Unidade por conta das situações de violação de direitos dos internos. Houve constituição de um Grupo de Trabalho composto por representantes dos Conselhos, Secretários de Estado, dirigentes e servidores da FUNAC para elaboração, implementação e monitoramento do Plano Emergencial e disponibilização de autoridades da política pública de Segurança do Estado para assumir a direção da Unidade, objetivando restaurar as normas e sua tranquilidade. Registraram-se dois casos de reiteração e 15 casos de readmissão ao longo do ano de 2010. Também ocorreram 28 fugas, especificamente no Centro da Juventude Esperança.

Quanto ao tipo de ato infracional praticado, sobressai-se no Estado a prática de roubo $(24,4 \%)$, seguido de homicídio (19\%) e sanção/ descumprimento de medida $(15,6 \%)$.

Tabela 10 - Adolescentes com internação, por procedência - Maranhão, 2010

\begin{tabular}{l|c|c|c}
\hline \multicolumn{1}{c|}{ Unidade } & Capital & Interior/outros estados & Total \\
\hline Centro da Juventude Esperança & 95 & 37 & 132 \\
\hline Centro da Juventude Florescer & 06 & 09 & 15 \\
\hline Total & 101 & 46 & 147 \\
\hline
\end{tabular}

Fonte: (MARANHÃO, 2010a). 


\section{CONCLUSÃO}

A violência estrutural e simbólica da qual padecem as famílias e adolescentes maranhenses deixam muito a desejar na área da Assistência Social e dos direitos humanos no Estado do Maranhão, do que são exemplo a permanência dos péssimos indicadores sociais e 0 caos no atendimento socioeducativo.

A realidade de pobreza que assola o estado há décadas permanece e se agrava, na medida em que 0 acesso reduzido da população, em especial a que se encontra naquela condição, impede que a maioria das famílias consiga ter seus direitos fundamentais assegurados.

A parcela da população mais afetada com essa realidade é, sem dúvida, o universo de crianças e adolescentes que se encontra submetido à educação sem qualidade, baixa cobertura dos serviços de saúde e saneamento e condições insalubres de moradia.

A título de exemplo, vale retomar a cobertura do Programa Bolsa Família e do PETI.

Em 2010, o Programa Bolsa Família no Maranhão alcançou o número de 856.454 famílias participantes (CEF, 2010 apud MARANHÃO, 2010b). O público a ser atendido era da ordem de 1.075 .986 famílias, enquanto a estimativa de famílias pobres, de acordo com o Perfil Bolsa Família alcançava apenas 859.489 famílias. Dessa forma, 216.497 deixaram de ser atendidas pelo Programa. O número de participantes no PBF em 2010 estava bem próximo do número de famílias identificado com o critério do Perfil Bolsa Família, mas representa apenas 80\% do número calculado pelo Perfil Cadastro Único, portanto, $20 \%$ das famílias pobres deixaram de ser atendidas.

O Censo 2010 do IBGE identificou cerca de 144 mil crianças e adolescentes na faixa etária entre 10 e 17 anos trabalhando no Maranhão. Desse total, quase 61 mil tinha idade entre 10 e 14 anos e perto de 83 mil estavam na faixa etária entre 15 e 17 anos (INSTITUTO BRASILEIRO DE GEOGRAFIA E ESTATÍSTICA, 2010).
O Censo 2010 mostrou que cerca de 76 mil crianças e adolescentes entre 10 e 17 anos, trabalhavam em atividades agrícolas e que um contingente de cerca de 22 mil meninos e meninas foram identificados no serviço urbano. $E$ também apontou a existência de 12 mil crianças e adolescentes realizando serviços domésticos no Estado do Maranhão (INSTITUTO BRASILEIRO DE GEOGRAFIA E ESTATÍSTICA, 2010).

Os dados indicam 0 desrespeito à legislação, as dificuldades de permanência das crianças e adolescentes no sistema escolar, abandono escolar e distorção idade-série além da ausência de políticas de trabalho e renda.

A consequência desse quadro é percebida, entre outros aspectos, nos índices elevados de violência cometida contra as crianças e adolescentes e de violação dos seus direitos.

Por fim, são notórios o desrespeito às diretrizes do SINASES, a reincidência de adolescentes nos atos infracionais e a regressão no sistema de atendimento socioeducativo, com 0 aumento da violência.

$\mathrm{O}$ debate sobre a redução da maioridade penal vem agravar esse quadro de fragilidade na proteção dos direitos das crianças e adolescentes. Funcionando como um repertório discursivo conservador, ataca os direitos conquistados no ECA, ainda em construção e repõe o discurso do menor delinquente, quando uma parte da sociedade ainda luta para consolidar a ideia do sujeito de direitos, em condição peculiar de desenvolvimento. Assim, a ideia de proteção é subsumida sob a ideia de sanção, punição e criminalização no contexto de uma sociedade demissionária de direitos, que não compreende as responsabilidades do Estado, sociedade e família com a geração futura que precisa ser protegida.

\section{REFERÊNCIAS}

BOURDIEU, Pierre. 0 poder simbólico. São Paulo: Bertrand, 1995. 
BRASIL. Lei $n^{0} 8.069$, de 13 de julho de 1990. Dispõe sobre o Estatuto da Criança e do Adolescente e dá outras providências. Brasília, DF, 1990.

BRASIL. Ministério da Saúde. Departamento de Informática do SUS. Portal da Saúde. Brasília, DF, 2010. Disponivel em:<http://tabnet.datasus.gov.br/ cgi/deftohtm.exe?ibge/cnv/popma.def>. Acesso em: 28 set. 2014.

Ministério do Desenvolvimento Social e Combate à Fome. Censo SUAS 2010. Brasília, DF, 2011. Disponivel em:<http://aplicacoes.mds.gov.br>. Acesso em: 28 set. 2014.

COSTA, Cândida da. Indicadores de assistência social. In: COSTA, Cândida da (Org.). Observatório criança: acompanhando a situação da criança do adolescente no Maranhão de 2006 a 2010. São Luís: CEDCA: CDMP, 2013.

Exclusão social no Maranhão. In: BORGES, Arleth Santos; COSTA, Cândida da; SILVA, Carmen Silvia Maria da. Vidas ameaçadas; indicadores da violação dos direitos de crianças e adolescentes no Maranhão de 1991 a 2000. São Luís: CDMP, 2000.

INSTITUTO BRASILEIRO DE GEOGRAFIA E ESTATÍSTICA. Censo Demográfico 2010: características da população e dos domicílios: resultados do universo. Rio de Janeiro, 2011. Disponível em:<http://www.ibge.gov.br/home/ estatistica/população/censo2010/default.shtm>. Acesso em: 21 maio 2013.

MARANHÃO. Secretaria de Direitos Humanos, Assistência Social e Cidadania. Fundação da Criança e do Adolescente. Relatório de Gestão do SUAS. São Luis, 2006.

SUAS. São Luís, 2007.

Relatório de Gestão do

Relatório de Gestão do

SUAS. São Luís, 2008.

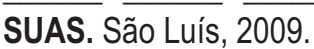

Relatório de Gestão do

Relatório de Gestão do
Relatório de Gestão da SEDES.

São Luís, 2010b.

PROGRAMA DAS NAÇÕES UNIDAS PARA O DESENVOLVIMENTO. Relatório de Desenvolvimento Humano Brasil 2009/2010: valores e desenvolvimento humano. Brasília, DF, 2010. Disponivel em:<www.pnud.org.br>. Acesso em: 28 set. 2014.

SANTOS, Boaventura Sousa. A construção multicultural da igualdade e da diferença. Rio de Janeiro: Congresso da SBS, 1995. (Mimeo).

NOTA

${ }^{1}$ Informação do site do MDS. Disponível em:<http://www.mds. gov.br/saladeimprensa/noticias/2014/setembro/brasil-reduziua-pobreza-em-suas-varias-dimensoes-revelou estudo-dobanco-mundial>. Acesso em: 28 set. 2014.

\section{Cândida da Costa}

Assistente Social

Doutora em Ciências Sociais pela pela Universidade Federal do Rio Grande do Norte (UFRN)

Coordenadora da Pesquisa Observatório Criança e Professora do Departamento de Serviço Social da Universidade Federal do Maranhão (UFMA)

E-mail: candida.costa@gmail.com

Universidade Federal do Maranhão - UFMA

Av. dos Portugueses, 1966 - Bacanga, São Luís - MA CEP: $65080-805$

SUAS. São Luís, 2010a. 